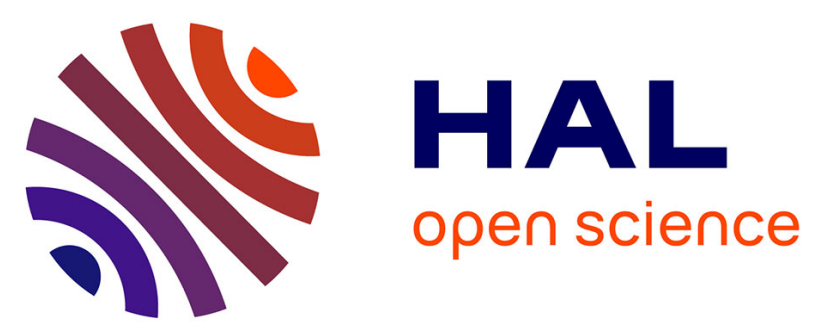

\title{
Expression of aberrantly glycosylated Mucin-1 in ovarian cancer
}

Catharina H.M.J. van Elssen, Peter W.H. Frings, Freek J. Bot, Koen K van de Vijver, Mariska B Huls, Bob Meek, Pierre Hupperets, Wilfred T.V.

Germeraad, Gerard M.J. Bos

\section{To cite this version:}

Catharina H.M.J. van Elssen, Peter W.H. Frings, Freek J. Bot, Koen K van de Vijver, Mariska B Huls, et al.. Expression of aberrantly glycosylated Mucin-1 in ovarian cancer. Histopathology, 2010, 57 (4), pp.597. 10.1111/j.1365-2559.2010.03667.x . hal-00586995

\section{HAL Id: hal-00586995 https://hal.science/hal-00586995}

Submitted on 19 Apr 2011

HAL is a multi-disciplinary open access archive for the deposit and dissemination of scientific research documents, whether they are published or not. The documents may come from teaching and research institutions in France or abroad, or from public or private research centers.
L'archive ouverte pluridisciplinaire HAL, est destinée au dépôt et à la diffusion de documents scientifiques de niveau recherche, publiés ou non, émanant des établissements d'enseignement et de recherche français ou étrangers, des laboratoires publics ou privés. 


\section{Histopathology}

\section{Expression of aberrantly glycosylated Mucin-1 in ovarian cancer}

\begin{tabular}{|c|c|}
\hline Journal: & Histopathology \\
\hline Manuscript ID: & HISTOP-10-09-0605.R1 \\
\hline Manuscript Type: & Original Article \\
\hline $\begin{array}{r}\text { Date Submitted by the } \\
\text { Author: }\end{array}$ & $10-F e b-2010$ \\
\hline Complete List of Authors: & $\begin{array}{l}\text { Van Elssen, Catharina; Maastricht University medical center+, } \\
\text { Internal medicine } \\
\text { Frings, Peter; Maastricht University Medical Center+, Internal } \\
\text { medicine } \\
\text { Bot, Freek; Maastricht University Medical Center+, Pathology } \\
\text { Van de Vijver, Koen; Maastricht University Medical Center+, } \\
\text { Pathology } \\
\text { Huls, Mariska; Maastricht University Medical Center+, Internal } \\
\text { medicine } \\
\text { Meek, Bob; Maastricht University Medical Center+, Internal } \\
\text { medicine } \\
\text { Hupperets, Pierre; Maastricht University Medical Center+, Intenal } \\
\text { medicine, oncology } \\
\text { Germeraad, Wilfred; Maastricht University Medical Center+, } \\
\text { Internal medicine; Maastricht University Medical Center+, Internal } \\
\text { medicine } \\
\text { Bos, Gerard; Maastricht University Medical Center+, Internal } \\
\text { medicine }\end{array}$ \\
\hline Keywords: & $\begin{array}{l}\text { Tn/STn-epitopes, glycosylation, ovarian adenocarcinoma, Tumour } \\
\text { associated antigen, glycosylation }\end{array}$ \\
\hline
\end{tabular}

\section{S ScholarONE" \\ Manuscript Central}




\section{Expression of aberrantly glycosylated Mucin-1 in ovarian cancer}

Catharina H.M.J. Van Elssen ${ }^{1,2}$, Peter W.H. Frings ${ }^{1}$, Freek J. Bot ${ }^{3}$, Koen K. Van de Vijver ${ }^{3}$, Mariska B. Huls ${ }^{1}$, Bob Meek ${ }^{1}$, Pierre Hupperets ${ }^{4}$, Wilfred T.V. Germeraad ${ }^{1}$ and Gerard M.J. $\operatorname{Bos}^{1}$

${ }^{1}$ Department of Internal Medicine, Division of Haematology, Maastricht University Medical Center ${ }^{+}$, Maastricht, the Netherlands

${ }^{2}$ PharmaCell BV, Maastricht, the Netherlands

${ }^{3}$ Department of Pathology, Maastricht University Medical Center ${ }^{+}$, Maastricht, the Netherlands

${ }^{4}$ Department of Internal Medicine, Division of Oncology, Maastricht University Medical Center $^{+}$, Maastricht, The Netherlands

Address for correspondence: Catharina Van Elssen, Department of Internal Medicine, Maastricht University Medical Center ${ }^{+}$, PO Box 616, 6200 MD Maastricht, The Netherlands, Phone: +31-433881644 / Fax: +31-433884164, Email: j.vanelssen@immuno.unimaas.nl

Running title: Underglycosylated MUC1 in ovarian cancer

Keywords: Tn, STn, ovarian adenocarcinoma, tumour associated antigen, MUC1 and glycosylation 
Aims: Mucin 1 (MUC1) is an important tumour-associated antigen (TAA), both overexpressed and aberrantly glycosylated in adenocarcinomas. The objective of this study was to examine the MUC1-glycosylation status in primary ovarian adenocarcinomas and metastatic lesions.

Methods and results: Paraffin-embedded tissue sections of 37 primary ovarian adenocarcinomas representing all histotypes (22 serous, 5 mucinous, 2 clear cell, 8 endometrioid), 4 serous borderline tumours with intraepithelial carcinoma, 7 sections of ovarian endometriosis and 13 metastatic lesions were analysed by immuno-histochemistry. Non-neoplastic ovarian surface epithelium and serous cystadenomas were used as controls. All epithelia expressed MUC1 protein. Of primary tumours, $76 \%$ expressed the differentiation-dependent glycoform and $84 \%$ the cancer-associated glycoform (Tn/Sialyl-Tnepitopes). In metastatic lesions this was $77 \%$ and $85 \%$, respectively. Notably, in $57 \%$ of ovarian endometriosis and $75 \%$ of intraepithelial lesions, the cancer-associated MUC1 epitopes were expressed, whereas normal ovarian surface epithelium and serous cystadenomas did not express these epitopes.

Conclusions: The underglycosylated MUC1 epitopes are expressed by all histotypes of primary ovarian adenocarcinomas, by the vast majority of metastatic lesions and by ovarian cancer precursor lesions, whereas not by normal ovarian tissue. These results indicate that MUC1-associated Tn/STn-epitopes are important targets for immunotherapy and diagnostic imaging in ovarian cancer patients. 


\section{Introduction}

Ovarian cancer is the second most common gynaecological malignancy in developed countries, and the most common cause of death among women developing gynaecological cancer $^{1,2}$. The high mortality rate is ascribed to the fact that more than $60 \%$ of ovarian cancer patients already have advanced disease at diagnosis. Therefore, ovarian cancer is also referred to as "silent killer". Metastasis as well as intra-abdominal growth are frequent, because the malignantly transformed epithelium of the ovarian surface is continuous with the peritoneal mesothelium ${ }^{3}$.

The current treatment of ovarian cancer is surgical resection, followed by platinumbased chemotherapy. Despite advances in chemotherapy treatment, which have led to improved survival, relapse is still frequent in the majority of patients with advanced disease ${ }^{4}$. To improve overall survival of ovarian cancer patients there is an urgent need for new treatment options. Immunotherapy has been demonstrated to be successful in the treatment of cancer $^{5}$. For antibody-mediated immunotherapy or cancer vaccines to be successful, identification of tumour-associated antigens (TAA), against which an immune response is induced, is of utmost importance. Up to this moment there have been few candidate-TAAs identified for ovarian cancer and clinical effects are limited ${ }^{6}$.

An interesting TAA is Mucin 1 (MUC1), because it is overexpressed in most adenocarcinomas ${ }^{7-9}$. MUC1 is a protein expressed on the apical surface of most simple, secretory epithelia and on a variety of hematopoietic cells ${ }^{10,11}$. MUC1 is a transmembrane mucin with an extracellular domain made up largely of 20 amino acid tandem repeats. After translation, the MUC1 protein becomes modified by extensive $O$-glycosylation. Within each tandem repeat, two serines and three threonines represent five potential $O$-glycosylation sites. The extent of glycosylation mainly depends on the expression of tissue-specific glycosyltransferases ${ }^{8}$. Importantly, it has been demonstrated that in most adenocarcinomas 
and some haematological malignancies MUC1 is aberrantly glycosylated, has lost its apical expression and is secreted into the circulation ${ }^{12-16}$. Due to aberrant glycosylation of MUC1 on tumour cells, new glycosylation-specific peptides are revealed, including the MUC1associated $\mathrm{Tn} / \mathrm{STn}$-epitopes. These epitopes are generated when $O$-glycosylation is terminated immediately after the first N-acetylgalactosamine (GalNAc) addition (Figure 1) ${ }^{17,18}$. The mechanisms responsible for $\mathrm{Tn}$ - and STn formation are still ill understood. It has been shown that alterations in ST6GalNAc-I transferase induces premature termination of glycosylation and subsequently enhances STn formation ${ }^{19}$. Another documented mechanism involves somatic mutation of the Cosmc gene, a molecular chaperone regulating the enzyme responsible for the addition of galactose (Gal) to the first GalNAC ${ }^{20}$. MUC1-associated Tnand STn-epitopes, both recognized by MAb $5 \mathrm{E} 5{ }^{18,21,22}$, are potential TAAs, which can be targeted in immunotherapy but are also of importance in diagnostic imaging ${ }^{17,23}$.

Over-expression of MUC1 has been reported in ovarian cancer ${ }^{24,25}$. The expression of MUC1-associated Tn/STn-epitopes has been suggested ${ }^{26}$, based on a similar expression pattern of MUC1 epitopes as well as Tn/STn-epitopes. However, the expression of MUC1associated Tn- and STn-epitopes has never been proven.

In this study, we determined whether primary ovarian tumours and metastatic lesions express aberrantly glycosylated MUC1. Since the most widely accepted candidate for the origin of ovarian cancer is the ovarian surface epithelium (OSE) ${ }^{27}$, we examined the MUC1 glycosylation status of OSE adjacent to the tumour in neoplasic ovaria and the epithelium of serous cystadenomas. Additionally, we analysed MUC1 expression of ovarian endometriosis and serous borderline tumours with intraepithelial carcinoma / micropapillary growth, because both have been reported to be precursor lesions of invasive ovarian adenocarcinomas ${ }^{28}$. We demonstrate that the MUC1-associated Tn/STn-epitopes are expressed on all different ovarian 
cancer histotypes and their metastases, while they are absent in normal ovarian tissue, rendering these epitopes potential targets for immunotherapy and immunodiagnostic imaging. 


\section{Materials and methods}

\section{TISSUE SAMPLES}

Paraffin-embedded tissue samples were obtained from files of the Department of Pathology, (Maastricht University Medical Center ${ }^{+}$) from 1990 to 2006. The study population consisted of 43 patients diagnosed with epithelial ovarian cancer. For 37 patients, primary tumours were analysed. For 8 of these patients, matched metastases were analysed. Of 5 other patients, only metastatic lesions could be analyed. As a control, normal OSE adjacent to the tumour of 9 MUC1 positive tumours and 7 serous cystadenomas were analysed.

The 37 primary ovarian tumours originated from different histotypes and comprised of 22 serous adenocarcinomas, 5 mucinous adenocarcinomas, 2 clear cell carcinomas, 8 endometrioid carcinomas. Additionally, 4 serous borderline tumours with intraepithelial carcinoma and 7 endometriosis lesions were analysed. The 8 matched metastatic lesions were all typed as serous adenocarcinomas and the 5 non-matched metastatic lesions consisted of 4 serous adenocarcinomas and 1 mucinous adenocarcinoma.

\section{ANTIBODIES}

MUC1 antibody 214D4 (purified from the supernatant of the 214D4 cell line ${ }^{29}$ ) was kindly provided by Dr. J. Hilkens (the Netherlands Cancer Institute, Amsterdam, the Netherlands). The MAb SM3 (supernatant ${ }^{30}$ ) was contributed by Prof. Dr. J. Taylor-Papadimitriou (Guy's Hospital, London, United Kingdom). MAb 5E5 (supernatant ${ }^{21,22}$ ) was donated by Prof. Dr. H. Clausen (Department of Glycobiology, University of Copenhagen, Denmark). A detailed description of the specificities of the MUC1 antibodies used in this study has been published previously ${ }^{18}$. Briefly, the MAb 214D4 recognizes human MUC1 irrespective of its glycosylation pattern, MAb SM3 recognizes the differentiation-dependent glycoforms and MAb 5E5 exclusively recognizes cancer-associated glycoforms of MUC1 (MUC1-associated 
Tn and STn) (Figure 1) ${ }^{21}$. Although the MAbs SM3 and 5E5 both display cancer-associated reactivity ${ }^{30}$, MAb SM3 also stains healthy human tissue as has been shown previously in the kidney and thymus 31,32 .

\section{IMMUNOHISTOCHEMISTRY}

Paraffin-embedded tissue sections were deparaffinised by xylol (Merck, Darmstadt, Germany) treatment and rehydrated in decreasing concentrations of methanol (Merck). After rehydration, endogenous peroxidase was blocked $\left(0.5 \% \mathrm{H}_{2} \mathrm{O}_{2}\right.$ in methanol) for 30 minutes and the slides were washed in PBS (Sigma-Aldrich, St. Louis, USA) supplemented with $0.05 \%$ Tween 20 (Merck). Specific staining of MUC1 was determined by incubation with primary anti-MUC1 MAbs or matched isotype controls overnight at $4{ }^{\circ} \mathrm{C}$. Afterwards, sections were rinsed with PBS / Tween 20 and incubated with Envision-HRP (DAKO, Glostrup, Denmark) for 20 minutes at room temperature. The colour was developed by incubation for 3 minutes at room temperature using a substrate buffer containing 3,3'-diaminobenzidine (5 $\mu \mathrm{g} / \mathrm{mL}$; DAKO) and 0.5\% $\mathrm{H}_{2} \mathrm{O}_{2}$ (Sigma, Zwijndrecht, the Netherlands) in PBS / Tween 20. Cytospins of the breast carcinoma cell line ZR75-1 (Department of Pathology, Maastricht University Medical Center ${ }^{+}$) proven to stain positive for all anti-MUC1 MAbs served as intraexperimental positive control for all antibodies ${ }^{32}$. The histological images were analysed by microscope (Carl Zeiss, Sliedrecht, the Netherlands) with an objective magnification of 1020x. Digital pictures were taken by a Jenoptic camera (Carl Zeiss). The ovarian tumor slides were analysed independently by five investigators (C.V.E.; F.B.; M.H.; W.G.; K.V.d.V.). Staining of cytoplasm and cell membranes was evaluated and cells were considered positive when at least one of these components showed positive staining. 


\section{Results}

\section{EXPRESSION OF MUC1-ASSOCIATED TN/STN-EPITOPES IN OVARIAN CANCER} AND ADJACENT HEALTHY TISSUE

To determine the MUC1 glycosylation status, we stained normal and malignantly transformed ovarian epithelium with different MUC1 glycosylation-specific antibodies. Figure 2 shows a tissue section, containing normal OSE and malignantly transformed epithelium. Clearly, the MUC1 protein was expressed on the apical surface of normal ovarian epithelium, whereas the differentiation-dependent and cancer-associated glycoforms were not detected (Figure 2). In all 9 neoplastic ovarian tissue samples containing OSE, MUC1 expression of the normal epithelium was limited to the apical surface.

Strikingly, the malignantly transformed epithelium of the same ovary showed abundant expression of the MUC1 protein (Figure 2B), as well as the differentiationdependent and cancer-associated glycoforms of MUC1, detected by MAb SM3 and 5E5, respectively (Figure 2C, D). Furthermore, in some malignant cells apical expression of MUC1 was lost, and MUC1 was detected on the entire cell surface (Figure 2D, arrows).

As an additional control of benign ovarian epithelium, serous cystadenomas were analysed for expression of MUC1. All of these cysts (7/7) expressed the MUC1 protein (MAb 214D4) and also 29\% (2/7) expressed the differentiation-dependent glycoform, (MAb SM3) but none of them (0/7) the cancer-associated MUC1 glycoform (MAb 5E5).

\section{EXPRESSION OF MUC1 AND CANCER-ASSOCIATED MUC1 ON DIFFERENT} OVARIAN CANCER HISTOTYPES

Since there are four different epithelial ovarian cancer histotypes, all were examined using the panel of MUC1 glycosylation-specific antibodies. The prevalence differs for each histotype, with the serous adenocarcinoma being the most common type of epithelial ovarian cancer, 
and the clear cell and endometrioid adenocarcinoma being rare ${ }^{3}$. This was reflected in the number of tumours that was available for examination for each different histotype (22 serous adenocarcinomas, 5 mucinous adenocarcinomas, 2 clear cell carcinomas and 8 endometrioid adenocarcinomas). All ovarian cancer histotypes expressed MUC1 (37/37) (Table 1). The differentiation-dependent glycoform (MAb SM3) was found on $82 \%(18 / 22)$ of the serous, $60 \%(3 / 5)$ of the mucinous, $63 \%(5 / 8)$ of the endometrioid and on all of the clear cell $(2 / 2)$ adenocarcinomas. The cancer-associated glycoform (MAb 5E5) was expressed on 86\% $(19 / 22)$ of the serous (Figure 3A), 80\% (4/5) of the mucinous (Figure 3B), all of the clear cell $(2 / 2)$ (Figure 3C) and on $88 \%$ (7/8) of the endometrioid adenocarcinomas (Figure 3D).

In contrast to serous cystadenomas, ovarian endometriosis can serve as a precursor lesion of ovarian cancer, especially of the endometrioid and clear cell subtypes ${ }^{27}$. Since most of the endometrioid adenocarcinomas express the MUC1 cancer-associated glycoform, we investigated the MUC1 glycosylation pattern of ovarian endometriosis. All endometriosis lesions expressed MUC1 (7/7) (Figure 4A), the differentiation-dependent glycoform (MAb SM3) was expressed by $57 \%$ (4/7) and the cancer-associated glycoform (MAb 5E5) by 71\% $(5 / 7)$ of the endometriosis lesions (Figure 4B, C).

Additionally, serous borderline tumours with intraepithelial ovarian carcinoma, another precursor lesion of invasive ovarian adenocarcinoma, was examined for its MUC1 expression. All of these lesions expressed the MUC1 protein (4/4) (Figure 5A), 50\% (2/4) the differentiation-dependent glycoform (Figure 5B) and 75\% (3/4) the cancer-associated glycoform (Figure 5C)

In summary, the MUC1-associated Tn/STn-epitopes could be detected in tissue sections of all different ovarian cancer histotypes. Importantly, these epitopes were expressed on $86 \%$ of the serous adenocarcinomas, the most frequently diagnosed ovarian malignancy. For the other histotypes the number of tumour sections analysed was too low to draw firm 
conclusions, but all tumours and ovarian cancer precursor lesions examined, expressed the cancer-associated MUC1 epitopes.

\section{EXPRESSION OF MUC1 AND CANCER-ASSOCIATED MUC1 IN OVARIAN CANCER} METASTASES

As already indicated, ovarian tumours are prone to metastasize, therefore metastatic lesions were examined for their MUC1 expression. In 8 cases, it was possible to analyze both the primary tumour as well as the metastases. In the metastatic lesions, expression of MUC1 was detected in all (13/13) of the samples (Figure 6B). The differentiation-dependent MUC1 glycoform was detected in 77\% (10/13) and the cancer-associated MUC1 glycoform in $85 \%$ (11/13) of metastatic lesions (Figure 6C, D). When the MUC1 expression profile of the metastases was compared with the profile of the primary tumour, the expression of MUC1 (MAb 214D4) was similar (100\%). Additionally, in 63\% (5/8) there was a similar expression profile of the differentiation-dependent MUC1 glycoform (MAb SM3) and even better results were obtained for the expression of MUC1-associated Tn/STn-epitopes (MAb 5E5), which showed comparable expression in all cases. 


\section{Discussion}

We demonstrate that aberrantly glycosylated, cancer-associated MUC1 is expressed in situ in most ovarian cancer tumours, but not in OSE and serous cystadenomas. Moreover, we show that the cancer-associated MUC1 epitopes are not only present in primary tumours, but also in ovarian cancer precursor lesions and in metastatic lesions. The expression of cancerassociated MUC1 epitopes in breast cancer has already been identified ${ }^{21}$. Until now, the presence of cancer-associated MUC1 specific Tn- and STn-epitopes in ovarian cancer has been suggested, but not yet proven ${ }^{26}$. Here we show that the cancer-associated MUC1 $\mathrm{Tn} / \mathrm{STn}$-epitopes, recognized by MAb 5E5, are indeed expressed in ovarian cancer and not in healthy ovarian tissue. In accordance with previous reports, the MAb SM3 also reacts with ovarian cancer tissue ${ }^{30}$. Even though the MAbs SM3 and 5E5 both display this cancerassociated reactivity in ovarian cancer, MAb SM3 also reacts with healthy tissue as has been shown previously in thymus, salivary glands, sebaceous glands and the distal tubulus of the kidney ${ }^{31,32}$. This indicates that antibodies recognizing MUC1-associated Tn/STn-epitopes might have more potential to be used in ovarian cancer diagnostics and especially in immunotherapy.

Several studies have reported on the monoclonality of most epithelial cells in endometriotic cysts ${ }^{33,34}$ and therefore endometriosis is classified as a tumour-like lesion ${ }^{28}$. The fact that the epithelium of ovarian endometriosis also expresses the MUC1-associated $\mathrm{Tn} / \mathrm{STn}$-epitopes, further supports the theory that endometriosis is actually a precursor lesion of ovarian cancer ${ }^{27}$. Molecular events involved in the transformation of endometriosis have been studied extensively ${ }^{27,35}$ and decreased glycosylation of MUC1 may be a marker of this process. This is supported by the expression of MUC1-associated Tn/STn-epitopes by serous borderline tumours with intraepithelial carcinoma, which is confirmed to be a precursor of invasive serous adenocarcinomas. If antibodies recognizing the MUC1-associated Tn/STn- 
epitopes are suitable for discrimination between high and low risk endometriosis lesions, this will improve risk assessment and possibly therapy of younger women who want to preserve fertility. However, before being used in routine diagnostics, larger series of endometriosis lesions and ovarian tumours have to be analysed and related to clinical outcome in a comparative study.

MUC1 is immunogenic, both humoral and cellular immune responses against normal and underglycosylated MUC1 have been identified ${ }^{15}$. Humoral immune responses have been confirmed by the detection of anti-MUC1 antibodies in the serum of healthy women and in women with ovarian cancer ${ }^{16,36}$. Anti-MUC1 antibody levels tend to be lower in cancer patients, which is possibly caused by the formation of immune-complexes with serum-MUC1 37. These anti-MUC1 antibodies have been shown to mediate antibody-dependent cellular cytotoxicity (ADCC) of MUC1 positive cancer cells and to be protective in cancer development ${ }^{38,39}$.

Despite its immunogenicity ${ }^{23,29,40}$, MUC1 also contributes to escape from tumour immuno-surveillance and metastasis formation. In tumour cells, MUC1 has an anti-adhesive function, which is not only of importance in cancer development ${ }^{40}$, but might be responsible for a diminished adherence of immune effector cells to the malignant cells ${ }^{41}$.

Immunotherapy will be essential to enhance immune responses to MUC1. MUC1 peptide vaccination or peptide-pulsed DC vaccination have shown to increase the amount of anti-MUC1 antibodies and induce proliferation of MUC1-specific cytotoxic T cells ${ }^{15,42-44}$. However, induction of a clinical effective cellular or humoral immune response to MUC1 has not yet been achieved. One of the reasons might be central tolerance to the mature MUC1 protein ${ }^{21}$. Thymic medullary epithelial cells express the MUC1 protein, thereby most likely inducing negative selection of MUC1-specific $\mathrm{T}$ cells. However, the underglycosylated MUC1 isoforms are not present in the thymus, and therefore it was suggested by our group, 
that tolerance is induced only to the mature MUC1 and not the MUC1-associated Tn/STnepitopes $^{32}$.

In this study, the underglycosylated MUC1-associated Tn/STn-epitopes were identified as potential TAAs, which could be used as targets for immunotherapy and immunodiagnostics in ovarian cancer patients and patients who are diagnosed with ovarian cancer precursor lesions. The expression of these epitopes by ovarian cancer and precursor lesions indicates that there are alterations in MUC1 processing and elucidation of the mechanism behind these alterations might increase our knowledge on ovarian tumour biology. Cancer-specific MUC1 is expressed in $86 \%$ of all different ovarian cancer histotypes and in $85 \%$ of metastatic lesions, but not in normal ovarian tissue. Moreover, in the most frequent histotype, the serous adenocarcinoma, the percentage of tumours expressing the cancerassociated MUC1 is high (86\%). Additionally, antibodies recognizing MUC1-associated Tn/STn-epitopes represent an effective diagnostic tool for the detection of ovarian cancer cells in tissue and fluids. Finally, since the MUC1-associated Tn/STn antibodies exclusively detect tumour cells, these antibodies could be effectively used for antibody-mediated immunotherapy and additionally radio-labelling could be very useful for in vivo imaging and therapy. 


\section{Acknowledgements}

We thank Prof. Dr. R. Kruitwagen (gynecological oncology) for critical reading of the manuscript. This work was supported by SenterNovem (Project: IS055002). The authors have no conflicting financial interests. 


\section{References}

1. Jemal A, Siegel R, Ward E, Hao Y, Xu J, Thun MJ. Cancer statistics, 2009. CA Cancer J Clin 2009;59;225-249.

2. Parkin DM, Bray F, Ferlay J, Pisani P. Global cancer statistics, 2002. CA Cancer J Clin 2005;55;74-108.

3. Cannistra SA. Cancer of the ovary. N Engl J Med 2004;351;2519-2529.

4. Salzberg M, Thurlimann B, Bonnefois H, Fink D, Rochlitz C, von Moos R, Senn H. Current concepts of treatment strategies in advanced or recurrent ovarian cancer. Oncology 2005;68;293-298.

5. Iannello A, Ahmad A. Role of antibody-dependent cell-mediated cytotoxicity in the efficacy of therapeutic anti-cancer monoclonal antibodies. Cancer Metastasis Rev 2005;24;487-499.

6. Frederick PJ, Straughn JM, Jr., Alvarez RD, Buchsbaum DJ. Preclinical studies and clinical utilization of monoclonal antibodies in epithelial ovarian cancer. Gynecol Oncol 2009;113;384-390.

7. Singh AP, Senapati S, Ponnusamy MP, Jain M, Lele SM, Davis JS, Remmenga S, Batra SK. Clinical potential of mucins in diagnosis, prognosis, and therapy of ovarian cancer. Lancet Oncol 2008;9;1076-1085.

8. Gendler SJ. MUC1, the renaissance molecule. J Mammary Gland Biol Neoplasia 2001;6;339-353.

9. Taylor-Papadimitriou J, Burchell J, Miles DW, Dalziel M. MUC1 and cancer. Biochim Biophys Acta 1999;1455;301-313.

10. Ho SB, Niehans GA, Lyftogt C, Yan PS, Cherwitz DL, Gum ET, Dahiya R, Kim YS. Heterogeneity of mucin gene expression in normal and neoplastic tissues. Cancer Res 1993;53;641-651.

11. Brayman M, Thathiah A, Carson DD. MUC1: a multifunctional cell surface component of reproductive tissue epithelia. Reprod Biol Endocrinol 2004;2;4.

12. Cloosen S, Gratama J, van Leeuwen EB, Senden-Gijsbers BL, Oving EB, von Mensdorff-Pouilly S, Tarp MA, Mandel U, Clausen H, Germeraad WT, Bos GM. Cancer specific Mucin-1 glycoforms are expressed on multiple myeloma. $\mathrm{Br} \mathrm{J}$ Haematol 2006;135;513-516.

13. Ichige K, Perey L, Vogel CA, Buchegger F, Kufe D. Expression of the DF3-P epitope in human ovarian carcinomas. Clin Cancer Res 1995; 1;565-571.

14. Burchell JM, Mungul A, Taylor-Papadimitriou J. O-linked glycosylation in the mammary gland: changes that occur during malignancy. J Mammary Gland Biol Neoplasia 2001;6;355-364.

15. von Mensdorff-Pouilly S, Gourevitch MM, Kenemans P, Verstraeten AA, Litvinov SV, van Kamp GJ, Meijer S, Vermorken J, Hilgers J. Humoral immune response to polymorphic epithelial mucin (MUC-1) in patients with benign and malignant breast tumours. Eur J Cancer 1996;32A;1325-1331.

16. Richards ER, Devine PL, Quin RJ, Fontenot JD, Ward BG, McGuckin MA. Antibodies reactive with the protein core of MUC1 mucin are present in ovarian cancer patients and healthy women. Cancer Immunol Immunother 1998;46;245-252.

17. Springer GF. T and Tn, general carcinoma autoantigens. Science 1984;224;1198-1206. 18. van Leeuwen EB, Cloosen S, Senden-Gijsbers BL, Agervig Tarp M, Mandel U, Clausen H, Havenga MJ, Duffour MT, Garcia-Vallejo JJ, Germeraad WT, Bos GM. Expression of aberrantly glycosylated tumor mucin-1 on human DC after transduction with a fiber-modified adenoviral vector. Cytotherapy 2006;8;24-35. 
19. Marcos NT, Pinho S, Grandela C, Cruz A, Samyn-Petit B, Harduin-Lepers A, Almeida R, Silva F, Morais V, Costa J, Kihlberg J, Clausen H, Reis CA. Role of the human ST6GalNAc-I and ST6GalNAc-II in the synthesis of the cancer-associated sialyl-Tn antigen. Cancer Res 2004;64;7050-7057.

20. Ju T, Lanneau GS, Gautam T, Wang Y, Xia B, Stowell SR, Willard MT, Wang W, Xia JY, Zuna RE, Laszik Z, Benbrook DM, Hanigan MH, Cummings RD. Human tumor antigens Tn and sialyl Tn arise from mutations in Cosmc. Cancer Res 2008;68;1636-1646.

21. Sorensen AL, Reis CA, Tarp MA, Mandel U, Ramachandran K, Sankaranarayanan V, Schwientek T, Graham R, Taylor-Papadimitriou J, Hollingsworth MA, Burchell J, Clausen H. Chemoenzymatically synthesized multimeric Tn/STn MUC1 glycopeptides elicit cancerspecific anti-MUC1 antibody responses and override tolerance. Glycobiology 2006;16;96107.

22. Tarp MA, Sorensen AL, Mandel U, Paulsen H, Burchell J, Taylor-Papadimitriou J, Clausen $\mathrm{H}$. Identification of a novel cancer-specific immunodominant glycopeptide epitope in the MUC1 tandem repeat. Glycobiology 2007;17;197-209.

23. Karsten U, von Mensdorff-Pouilly S, Goletz S. What makes MUC1 a tumor antigen? Tumour Biol 2005;26;217-220.

24. Giuntoli RL, 2nd, Rodriguez GC, Whitaker RS, Dodge R, Voynow JA. Mucin gene expression in ovarian cancers. Cancer Res 1998;58;5546-5550.

25. Feng H, Ghazizadeh M, Konishi H, Araki T. Expression of MUC1 and MUC2 mucin gene products in human ovarian carcinomas. Jpn J Clin Oncol 2002;32;525-529.

26. Tashiro Y, Yonezawa S, Kim YS, Sato E. Immunohistochemical study of mucin carbohydrates and core proteins in human ovarian tumors. Hum Pathol 1994;25;364-372.

27. Mandai M, Yamaguchi K, Matsumura N, Baba T, Konishi I. Ovarian cancer in endometriosis: molecular biology, pathology, and clinical management. Int J Clin Oncol 2009; 14;383-391.

28. Scully RE. Classification of human ovarian tumors. Environ Health Perspect $1987 ; 73 ; 15-25$.

29. Wesseling J, van der Valk SW, Vos HL, Sonnenberg A, Hilkens J. Episialin (MUC1) overexpression inhibits integrin-mediated cell adhesion to extracellular matrix components. $\mathbf{J}$ Cell Biol 1995;129;255-265.

30. Burchell J, Gendler S, Taylor-Papadimitriou J, Girling A, Lewis A, Millis R, Lamport D. Development and characterization of breast cancer reactive monoclonal antibodies directed to the core protein of the human milk mucin. Cancer Res 1987;47;5476-5482.

31. Girling A, Bartkova J, Burchell J, Gendler S, Gillett C, Taylor-Papadimitriou J. A core protein epitope of the polymorphic epithelial mucin detected by the monoclonal antibody SM3 is selectively exposed in a range of primary carcinomas. Int J Cancer 1989;43;1072-1076.

32. Cloosen S, Arnold J, Thio M, Bos GM, Kyewski B, Germeraad WT. Expression of tumor-associated differentiation antigens, MUC1 glycoforms and CEA, in human thymic epithelial cells: implications for self-tolerance and tumor therapy. Cancer Res 2007;67;39193926.

33. Jimbo H, Hitomi Y, Yoshikawa H, Yano T, Momoeda M, Sakamoto A, Tsutsumi O, Taketani Y, Esumi H. Evidence for monoclonal expansion of epithelial cells in ovarian endometrial cysts. Am J Pathol 1997;150;1173-1178.

34. Nilbert M, Pejovic T, Mandahl N, Iosif S, Willen H, Mitelman F. Monoclonal origin of endometriotic cysts. Int J Gynecol Cancer 1995;5;61-63.

35. Gilks CB, Prat J. Ovarian carcinoma pathology and genetics: recent advances. Hum Pathol 2009;40;1213-1223. 
36. Croce MV, Isla-Larrain MT, Capafons A, Price MR, Segal-Eiras A. Humoral immune response induced by the protein core of MUC1 mucin in pregnant and healthy women. Breast Cancer Res Treat 2001;69;1-11.

37. Kotera Y, Fontenot JD, Pecher G, Metzgar RS, Finn OJ. Humoral immunity against a tandem repeat epitope of human mucin MUC-1 in sera from breast, pancreatic, and colon cancer patients. Cancer Res 1994;54;2856-2860.

38. Moreno M, Bontkes HJ, Scheper RJ, Kenemans P, Verheijen RH, von MensdorffPouilly S. High level of MUC1 in serum of ovarian and breast cancer patients inhibits huHMFG-1 dependent cell-mediated cytotoxicity (ADCC). Cancer Lett 2007;257;47-55.

39. Terry KL, Titus-Ernstoff L, McKolanis JR, Welch WR, Finn OJ, Cramer DW. Incessant ovulation, mucin 1 immunity, and risk for ovarian cancer. Cancer Epidemiol Biomarkers Prev 2007;16;30-35.

40. Nassar H, Pansare V, Zhang H, Che M, Sakr W, Ali-Fehmi R, Grignon D, Sarkar F, Cheng J, Adsay V. Pathogenesis of invasive micropapillary carcinoma: role of MUC1 glycoprotein. Mod Pathol 2004;17;1045-1050.

41. van de Wiel-van Kemenade E, Ligtenberg MJ, de Boer AJ, Buijs F, Vos HL, Melief CJ, Hilkens J, Figdor CG. Episialin (MUC1) inhibits cytotoxic lymphocyte-target cell interaction. J Immunol 1993;151;767-776.

42. Akporiaye ET, Bradley-Dunlop D, Gendler SJ, Mukherjee P, Madsen CS, Hahn T, Besselsen DG, Dial SM, Cui H, Trevor K. Characterization of the MUC1.Tg/MIN transgenic mouse as a model for studying antigen-specific immunotherapy of adenomas. Vaccine 2007;25;6965-6974.

43. Apostolopoulos V, Pietersz GA, Tsibanis A, Tsikkinis A, Drakaki H, Loveland BE, Piddlesden SJ, Plebanski M, Pouniotis DS, Alexis MN, McKenzie IF, Vassilaros S. Pilot phase III immunotherapy study in early-stage breast cancer patients using oxidized mannanMUC1 [ISRCTN71711835]. Breast Cancer Res 2006;8;R27.

44. Loveland BE, Zhao A, White S, Gan H, Hamilton K, Xing PX, Pietersz GA, Apostolopoulos V, Vaughan H, Karanikas V, Kyriakou P, McKenzie IF, Mitchell PL. Mannan-MUC1-pulsed dendritic cell immunotherapy: a phase I trial in patients with adenocarcinoma. Clin Cancer Res 2006;12;869-877. 


\section{Tables}

Table 1. Expression of the different MUC1glycoforms on the different ovarian carcinoma histotypes.

\begin{tabular}{lccc}
\hline Histotypes / MAb & 214D4 & SM3 & 5E5 \\
\hline Serous adnocarcinoma & $100 \%(22 / 22)$ & $82 \%(18 / 22)$ & $86 \%(19 / 22)$ \\
\hline Mucinous adenocarcinoma & $100 \%(5 / 5)$ & $60 \%(3 / 5)$ & $80 \%(4 / 5)$ \\
\hline Clear cell carcinoma & $100 \%(2 / 2)$ & $100 \%(2 / 2)$ & $100 \%(2 / 2)$ \\
\hline Endometrioid adenocarcinoma & $100 \%(8 / 8)$ & $63 \%(5 / 8)$ & $88 \%(7 / 8)$ \\
\hline
\end{tabular}


Figure 1

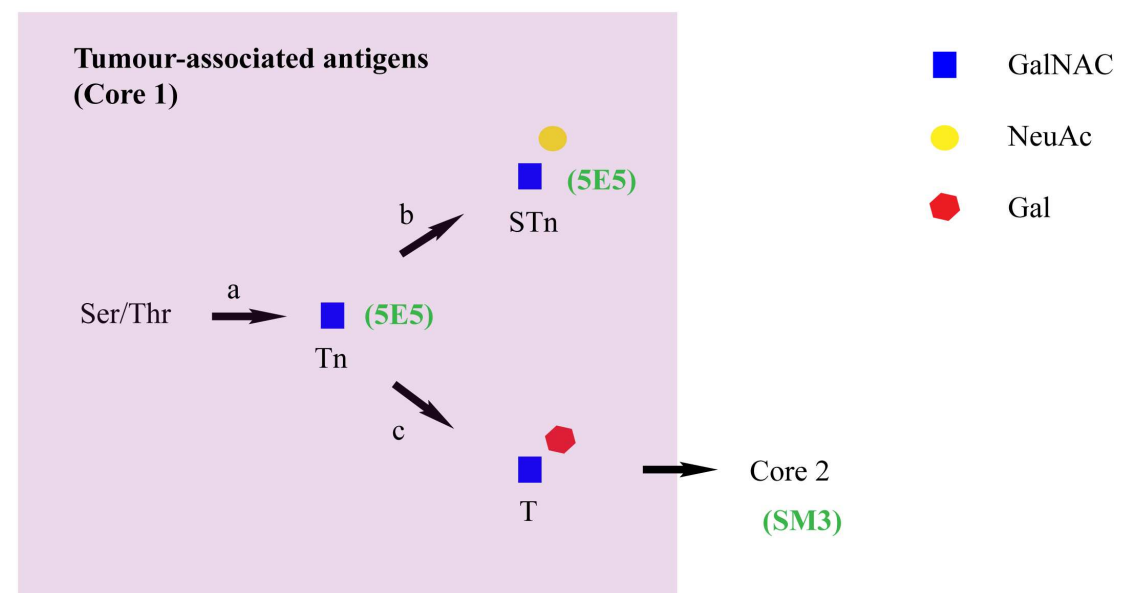

Figure 1. Schematic representation of carbohydrate antigens, MAb and glycosyltransferases assayed in this paper. O-linked glycosylation is initiated by polypeptide $\mathrm{N}$ - acetylgalactosaminyltransferases (a), adding N-acetylgalactosamine (GalNAc) to serine (Ser) or threonine (Thr) of the polypeptide backbone, resulting in the Tn antigen, recognised by MAb 5E5. The Tn antigen may be sialylated by sialyltransferase ST6GalNAc-I (b), adding sialic acid (NeuAc) to the GalNAc moiety of Tn, resulting in the sialyl-Tn (STn) antigen, also recognized by MAb 5E5. If not sialylated, core 1 structures may be synthesized by galactosyltransferase Core 1 B3-GalT (c), adding galactose (Gal) to the GalNAc moiety of Tn, resulting in the $T$ antigen. Addition of further sugar moieties will result in the formation of Core 2 antigen formation, recognised by MAb SM3.

$215 \times 128 \mathrm{~mm}(300 \times 300$ DPI $)$ 
Figure 2

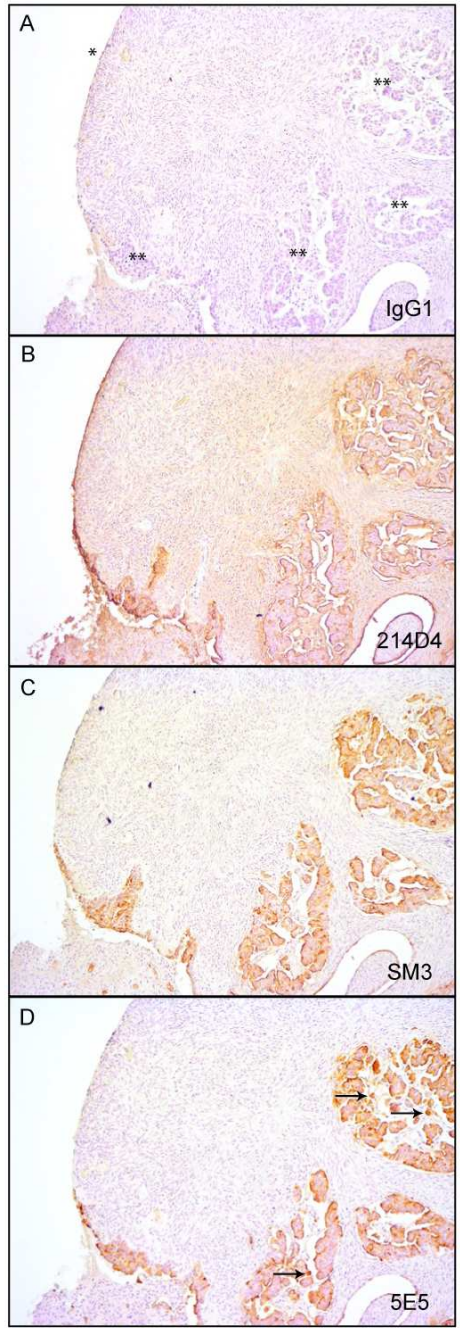

Figure 2. Expression of different MUC1 glycoforms on human ovarian tissue sections containing normal and malignant ovarian epithelium (serous adenocarcinoma). Sections were stained with mAb specific for MUC1 glycoforms. (A) Isotype control. (B) The glycosylated MUC1 isoform (MAb 214D4) was strongly expressed on the apical side of the normal epithelium, and on malignant transformed epithelium. (C) No expression of the differentiation-dependent glycoform of MUC1 (MAb SM3) in normal tissue while malignant transformed tissue stained positive. (D) The cancer-associated isoform of MUC1 (MAb 5E5) was not expressed on normal tissue, but was expressed on the malignant tissue. Loss of apical surface expression is indicated (D arrows). * Normal ovarian epithelium, ** malignantly transformed epithelium. $210 \times 297 \mathrm{~mm}(150 \times 150 \mathrm{DPI})$ 
Figure 3

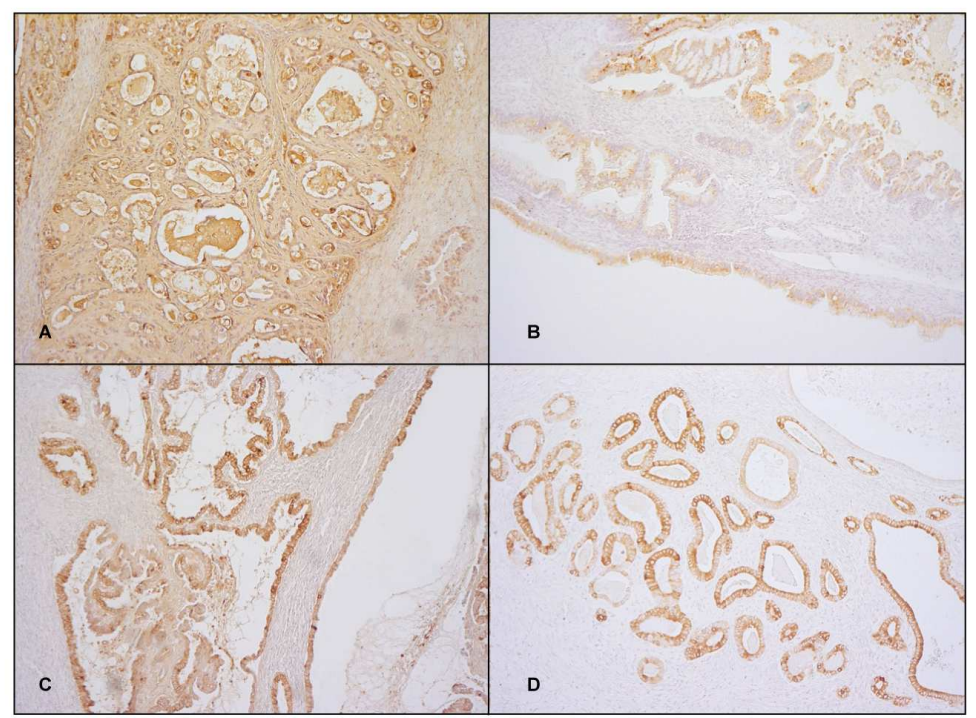

Figure 3. Expression of the cancer-associated glycoform of MUC1 (MAb 5E5) on the different ovarian cancer histotypes. (A) Serous adenocarcinoma. (B) Mucinous adenocarcinoma. (C) Clear cell carcinoma. (D) Endometrioid adenocarcinoma. $297 \times 210 \mathrm{~mm}(150 \times 150 \mathrm{DPI})$ 


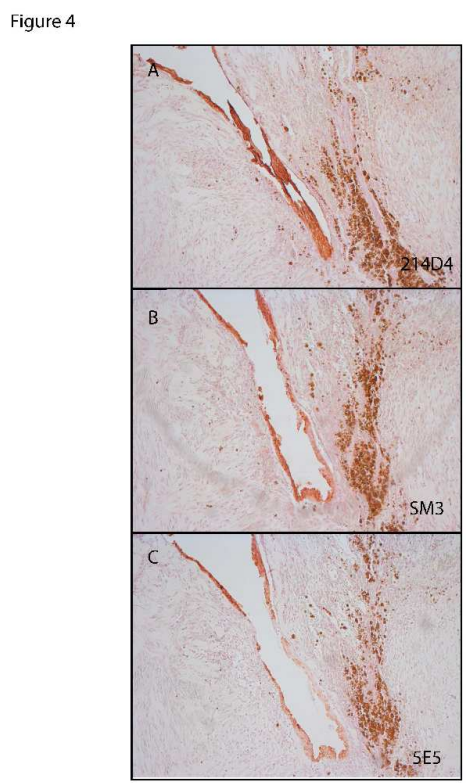

Figure 4. Expression of different MUC1 glycoforms in endometriosis of the ovary. (A) The glycosylated MUC1 isoform (MAb 214D4), (B) differentiation-dependent glycoform of MUC1 (MAb SM3) (c) and cancer-associated glycoform of MUC1 (MAb 5E5).

$282 \times 211 \mathrm{~mm}(600 \times 600 \mathrm{DPI})$ 


\section{Figure 5}

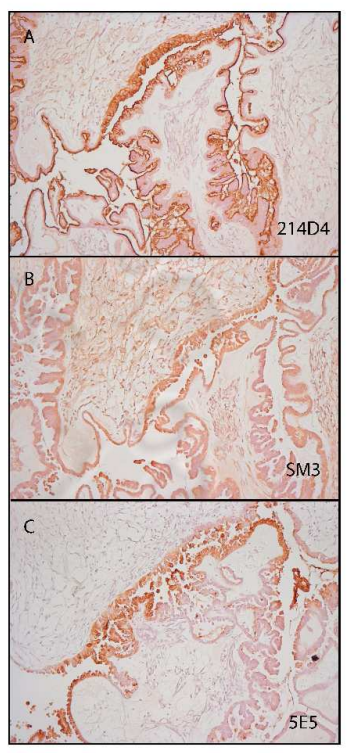

Figure 5. Expression of different MUC1 glycoforms in a serous borderline tumour with intraepithelial carcinoma. (A) The glycosylated MUC1 isoform (MAb 214D4), (B) differentiation-dependent glycoform of MUC1 (MAb SM3) (c) and cancer-associated glycoform of MUC1 (MAb 5E5).

$282 \times 211 \mathrm{~mm}(600 \times 600 \mathrm{DPI})$ 
Figure 6

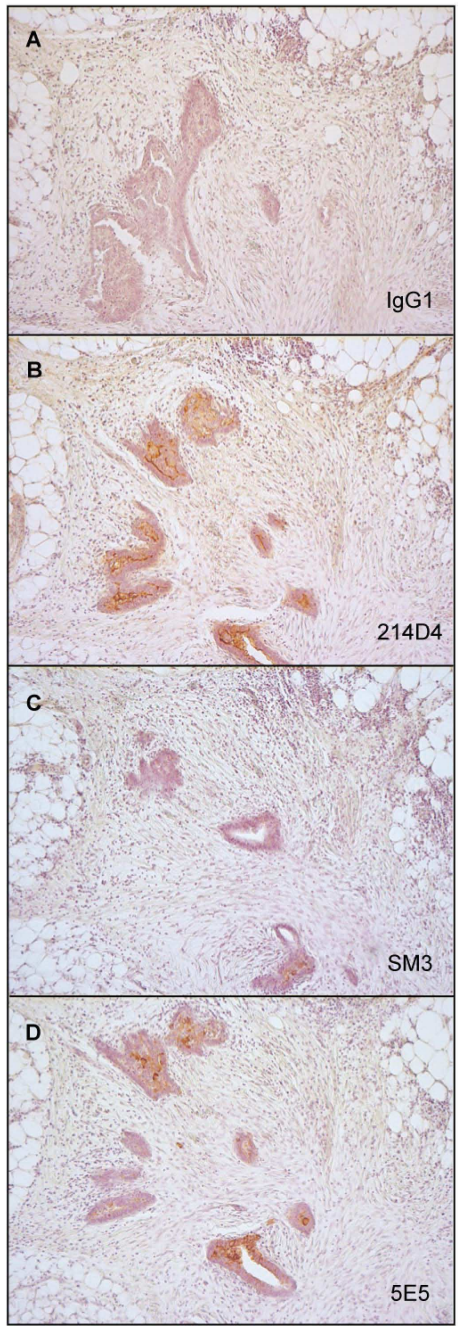

Figure 6. Expression of different MUC1 glycoforms in a metastatic ovarian cancer lesion in the omentum. (A) Staining with isotype control. (B) The glycosylated MUC1 isoform (MAb 214D4), (C) differentiation-dependent glycoform of MUC1 (MAb SM3) (D) and cancer-associated glycoform of MUC1 (MAb 5E5) were expressed in the metastatic lesion.

$210 \times 296 \mathrm{~mm}(300 \times 300 \mathrm{DPI})$ 